\title{
Osteopontin Plays a Critical Role in Interstitial Fibrosis but Not Glomerular Sclerosis in Diabetic Nephropathy
}

\author{
Tomoaki Nagao $^{a}$ Takafumi Okura $^{a}$ Jun Irita ${ }^{a}$ \\ Masanori Jotoku ${ }^{a}$ Daijiro Enomoto ${ }^{a}$ Veena Rasika Desilva ${ }^{a}$ \\ Ken-ichi Miyoshi $^{a}$ Mie Kurata ${ }^{a}$ Yutaka Matsui $^{\text {b }}$ \\ Toshimitsu Uede ${ }^{c}$ Jitsuo Higaki ${ }^{a}$ \\ a Department of Integrated Medicine and Informatics, Ehime University Graduate School \\ of Medicine, Ehime, and ${ }^{b}$ Department of Matrix Medicine and ${ }^{C}$ Division of Molecular \\ Immunology, Institute for Genetic Medicine, Hokkaido University, Sapporo, Japan
}

\section{Key Words}

Osteopontin $\cdot$ Interstitial fibrosis $\cdot$ Diabetic nephropathy

\begin{abstract}
Background/Aims: Osteopontin (OPN) has been implicated in the pathology of several renal conditions. The aim of this study was to clarify the roles of OPN in diabetic nephropathy. Methods: Diabetes mellitus (DM) was induced in wild-type (WT) and OPN knockout (KO) mice by injecting streptozotocin. The mice were killed 20 weeks after induction of DM and their kidneys removed. Results: Renal mRNA expression of OPN was increased in WT-DM mice compared to WT-sham mice. Immunohistochemistry showed high levels of OPN expression in the proximal tubules of WT-DM mice. Kidney weight and urinary albumin excretion increased to similar levels in the WT-DM and KO-DM mice. Interstitial fibrosis was increased in WT-DM mice compared to KO-DM mice. However, there were no differences in the degree of mesangial expansion or glomerular hypertrophy between the two groups. F4/80-positive cells (macrophages) and FSP-1positive cells (fibroblasts) showed significantly higher infiltration in WT-DM mice than in KO-DM mice. Renal mRNA expression of NADPH oxidase subunits and urinary 8-isoprostane excretion were also increased in WT-DM mice. Conclusions: These results indicated that OPN is a key molecule that induces interstitial fibrosis in the diabetic kidney, but does not induce glomerular sclerosis.




\section{Introduction}

Chronic kidney disease (CKD) is constituted predominantly by diabetes mellitus (DM) nephropathy, the pathological profile of which includes glomerulosclerosis, tubular atrophy, and interstitial fibrosis. Of these pathological changes, the tubulointerstitial component is most closely correlated with the progression of renal failure [1].

A number of cytokine systems including transforming growth factor- $\beta$ (TGF- $\beta$ ) 1 [2], angiotensin II [3], and osteopontin (OPN) have been implicated in tubulointerstitial injury. Microarray analyses identified OPN as one of the major genes upregulated in DM nephropathy [4]. OPN is a glycosylated phosphoprotein that contains an arginine-glycine-aspartate (RGD)-binding sequence that enables interaction with various integrins and CD44. OPN is produced by osteoblasts, macrophages, endothelial cells, and epithelial cells and acts by facilitating cell adhesion and migration [5]. In the normal kidney, OPN is expressed mainly in the loop of Henle and distal nephron. OPN expression has been shown to be upregulated in renal tubular cells and glomeruli in glomerulonephritis, hypertension, and ischemic acute renal failure [5].

Recently, it was reported that quantification of OPN immunostaining revealed a marked increase in the percentage of OPN-positive proximal tubular cells in human DM kidneys, which correlated strongly with the degree of cortical scarring [6]. This finding indicates that OPN expression may play a key role in the interstitial fibrosis associated with DM nephropathy.

The present study investigated the role of OPN in the pathogenesis of DM nephropathy. DM was induced in wild-type (WT) and OPN knockout (KO) mice by repeated intraperitoneal injections of streptozotocin (STZ). Interstitial fibrosis was increased in the WT-DM mice compared to the KO-DM mice. However, there were no differences in mesangial expansion and glomerular hypertrophy between the two groups. The data presented here suggest that increased expression of OPN in the DM kidney has a deleterious effect by increasing renal interstitial fibrosis, but not glomerular sclerosis.

\section{Materials and Methods}

\section{Animals}

$\mathrm{KO}$ mice were generated as described previously [7]. Eight-week-old male KO mice ( $\mathrm{n}=$ $11)$ and age-matched male C57BL/6 WT mice $(n=12)$ were used. All the mice were housed in a room with a 12-hour light/dark cycle, with the room temperature maintained at $24^{\circ} \mathrm{C}$. The experimental protocol was approved by the Animal Studies Committee of Ehime University. DM was induced by intraperitoneal injections of STZ $(50 \mathrm{mg} / \mathrm{kg}$ in citrate buffer, $\mathrm{pH}$ 4.2) for 5 days. Mice injected with the same volume of citrate buffer acted as sham controls. The mice had unlimited access to water and standard mouse chow. Plasma glucose levels were measured 7 days and every 4 weeks after the STZ injections. Animals with a plasma glucose level $>250 \mathrm{mg} / \mathrm{dl}$ at day 7 were considered diabetic and used for the 20 -week experiments. Measurements of systolic blood pressure were performed using the indirect tail-cuff method (MK-2000; Muromachi Kikai, Tokyo, Japan). Twenty-four-hour urine samples were collected in metabolic cages. At the end of the study, blood samples were obtained from the inferior vena cava and the kidneys were then removed and weighed. Coronal sections of the kidneys were fixed in 10\% formalin and then embedded in paraffin for histological evaluation. The remainder of the kidney was snap-frozen in liquid nitrogen for mRNA or immunohistochemical analysis. 


\section{Biochemical Measurements}

Urine albumin concentration was measured by an enzyme-linked immunosorbent assay (ELISA) commercial kit (EXOCELL, Philadelphia, Pa., USA) and serum creatinine by an automatic analyzer (Nagahama LSL, Shiga, Japan). Plasma OPN and urinary 8-isoprostane were also measured using commercially available ELISA kits (IBL, Gunma, Japan, and Detroit R\&D, Inc., Detroit, Mich., USA, respectively).

\section{Morphologic Analysis and Immunohistochemistry}

The kidney sections were stained with Periodic Acid-Schiff (PAS) and Masson's trichrome method. Cross sections of the PAS and Masson's trichrome stains were semi-quantified using NIH ImageJ software (http://rsb.info.nih.gov/ij/). Glomerular volume and mesangial area were quantified by scanning 10 non-overlapping glomeruli of each kidney section stained by PAS. The fibrotic blue staining areas by Masson's trichrome stains were also quantified by scanning 10 non-overlapping fields of each kidney section. Each positive area (glomerular volume, mesangial area, and interstitial fibrosis) was expressed as a percentage of the total area.

Immunohistochemistry was performed using Simple stain kits (Nichirei, Tokyo, Japan) according to the manufacturer's instructions. Briefly, paraffin-embedded sections were deparaffinized with xylene and then rehydrated in a descending series of ethanol. The sections were treated for 15 min with $3 \% \mathrm{H}_{2} \mathrm{O}_{2}$ in methanol to inactive endogenous peroxidase and then incubated at room temperature for $1 \mathrm{~h}$ with primary antibodies against either rabbit anti-OPN (1:50; IBL), rat anti-F4/80 (1:500; BMA, Augst, Switzerland), antiFSP-1 (1:100; Thermo, Miami, Fla., USA), $\alpha$-SMA (1:100; Abcam, Cambridge, UK), antiTGF- $\beta$ (1:50; Abcam) or anti-type IV collagen (1:500; Abcam). These positive stains with diaminobenzidine were quantified using ImageJ software by scanning 6 non-overlapping fields in each kidney section, and expressing the positive area as a percentage of the total area.

\section{RNA Isolation and Real-Time PCR}

Total RNA was isolated from the cortex of the kidney using ISOGEN (Nippon gene, Tokyo, Japan) according to the manufacturer's protocol. Gene expression was analyzed quantitatively by real-time RT-PCR using fluorescent SYBR Green technology (LightCycler; Roche Molecular Biochemicals). $\beta$-Actin cDNA was amplified and quantitated in each cDNA preparation in order to normalize the relative amounts of the target genes. The primer sequences were listed in the online supplementary table (for all online suppl. material, see www.karger.com/doi/10.1159/000337330).

\section{Protein Analysis}

Western blotting analysis was performed as described previously [8]. The lysates were separated on $10 \%$ polyacrylamide gels, followed by immunoblotting using rabbit anti-OPN (IBL). $\beta$-Actin (Cell Signaling Technology, Beverly, Mass., USA) was used to normalize the protein loaded on the blots. This analysis was carried out independently three times.

\section{Statistical Analysis}

Data are expressed as mean \pm SEM. For multiple comparisons, statistical analysis was performed by 2-way ANOVA and Scheffe's post-hoc test. The Mann-Whitney U test was used for comparisons between the two groups. $\mathrm{p}$ values $<0.05$ were considered statistically significant. 
Fig. 1. Blood glucose levels were measured in DM and sham mice (WT-sham, $\mathrm{n}=5$; WT-DM, $\mathrm{n}=7$; KO-sham, $\mathrm{n}=5$; KO-DM, $\mathrm{n}=7$ ). ${ }^{*} \mathrm{p}<0.05$ vs. WT-sham mice.

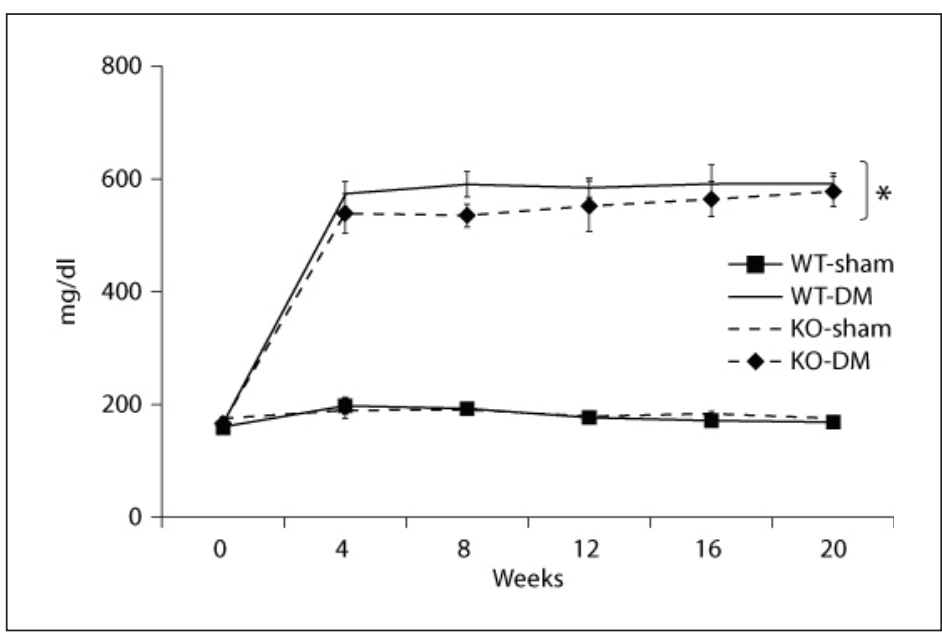

Table 1. Physiological and biological parameters in the four groups of mice

\begin{tabular}{|c|c|c|c|c|}
\hline & $\begin{array}{l}\text { WT-sham } \\
(\mathrm{n}=5)\end{array}$ & $\begin{array}{l}\text { WT-DM } \\
(\mathrm{n}=7)\end{array}$ & $\begin{array}{l}\text { KO-sham } \\
(\mathrm{n}=5)\end{array}$ & $\begin{array}{l}\text { KO-DM } \\
(\mathrm{n}=6)\end{array}$ \\
\hline Body weight, g & $33.0 \pm 1.8$ & $24.6 \pm 0.5^{*}$ & $36.4 \pm 1.5$ & $25.5 \pm 0.9^{*}$ \\
\hline Kidney weight, mg & $218 \pm 10$ & $293 \pm 12^{*}$ & $221 \pm 11$ & $293 \pm 18^{*}$ \\
\hline Blood pressure, $\mathrm{mm} \mathrm{Hg}$ & $119 \pm 7$ & $115 \pm 2$ & $111 \pm 7$ & $114 \pm 7$ \\
\hline Creatinine, mg/dl & $0.06 \pm 0.05$ & $0.10 \pm 0.08^{*}$ & $0.06 \pm 0.04$ & $0.07 \pm 0.04$ \\
\hline Urine albumin, $\mu \mathrm{g} /$ day & $40.2 \pm 6.5$ & $163.2 \pm 19.8^{*}$ & $18.1 \pm 5.2$ & $211.0 \pm 49.4^{*}$ \\
\hline Plasma OPN, ng/ml & $4,670 \pm 532$ & $6,552 \pm 763$ & & \\
\hline
\end{tabular}

Values are mean \pm SEM. ${ }^{*} \mathrm{p}<0.05$ vs. WT-sham and KO-sham mice.

\section{Results}

\section{DM and Increased OPN Expression}

Plasma glucose levels were increased in the WT-DM and KO-DM mice 60 days after STZ administration, with no significant difference between the two groups of mice (WT-DM 591 $\pm 19 \mathrm{mg} / \mathrm{dl}$; KO-DM $577 \pm 26 \mathrm{mg} / \mathrm{dl}$; fig. 1). Renal OPN gene and protein expression were evaluated by real-time PCR and Western blot analysis. The expression of OPN mRNA was significantly higher in WT-DM mice than in WT-sham mice (WT-DM $3.80 \pm 1.1$-fold; fig. 2a). The expression of OPN protein was increased by the induction of DM (fig. 2b). Immunohistochemical analysis showed that OPN protein was localized mainly in the medullary tubules in WT-sham mice and was upregulated markedly in the proximal tubules of WT-DM mice (fig. 2c). Plasma OPN tended to be increased in the WT-DM mice compared to the WT-sham mice, although this difference was not statistically significant (WT-sham $4,670 \pm 532.4 \mathrm{ng} / \mathrm{ml} ;$ WT-DM 6,552 $\pm 763.6 \mathrm{ng} / \mathrm{ml}$; table 1).

\section{Biological Parameters}

The physiological and biochemical data are presented in table 1. In the DM mice, body weight was decreased and kidney weight was increased compared to values in sham mice. Blood pressure at 20 weeks did not differ between the four groups. Urine albumin excretion was increased by the induction of DM, with similar levels in the WT-DM and KO-DM mice. 

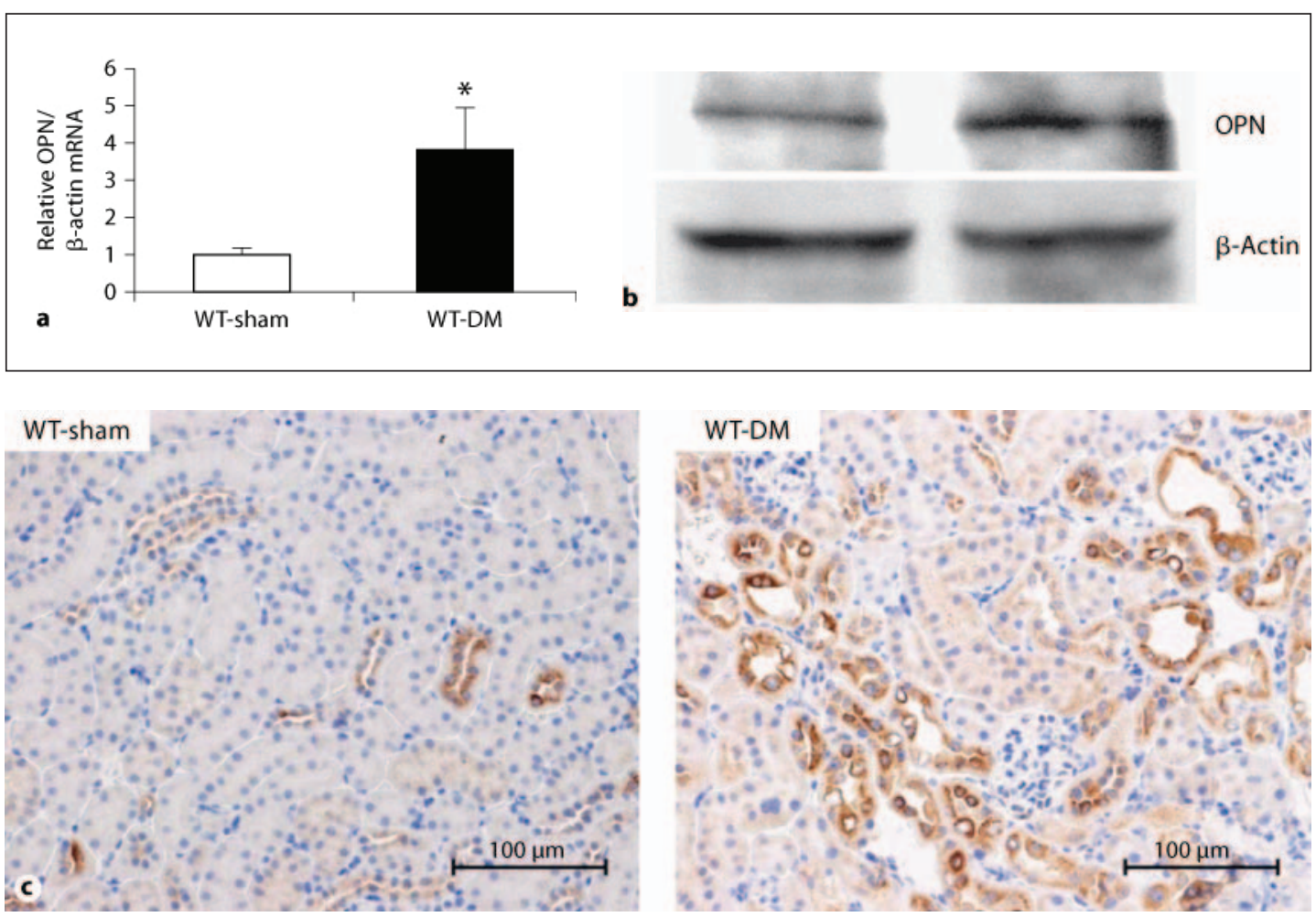

Fig. 2. Renal mRNA (a) and protein levels of OPN (b). RNA was isolated from the kidney for quantitative RT-PCR (WT-sham, $\mathrm{n}=5$; WT-DM, $\mathrm{n}=7$ ). Whole protein was isolated from the kidney for Western blotting (WT-sham, $\mathrm{n}=5$; WT-DM, $\mathrm{n}=7$ ). Values are expressed as mean \pm SEM. ${ }^{*} \mathrm{p}<0.05$. c Representative images of immunohistochemistry of OPN protein in WT-sham and WT-DM mice.

\section{Glomerular Injury}

In the PAS stains (fig. 3a-e), we found the same degree of glomerular hypertrophy (WTsham $1.0 \pm 0.02$; WT-DM $1.3 \pm 0.03$; KO-sham $1.2 \pm 0.04 ;$ KO-DM $1.4 \pm 0.04$; fig. $3 \mathrm{e}$ ) and mesangial matrix expansion (WT-sham $22.2 \pm$ 1.4\%; WT-DM $38.0 \pm 2.5 \%$; KO-sham 24.9 $\pm 1.0 \%$; KO-DM $33.3 \pm 2.5 \%$; fig. $3 f$ ) in the WT-DM and KO-DM mice. Immunohistochemical analysis showed that there were no significant differences of type IV collagen-positive areas among the four groups (WT-sham $20.0 \pm 1.5 \%$; WT-DM $28.6 \pm 2.1 \%$; KO-sham $22.0 \pm 4.6 \%$; KO-DM $27.5 \pm 1.2 \%$; fig. $3 \mathrm{~g}-\mathrm{k})$.

\section{Renal Interstitial Fibrosis}

Interstitial fibrosis was increased significantly in WT-DM mice, as shown by Masson's trichrome staining. However, importantly, interstitial fibrosis was diminished in KO-DM mice (WT-sham $4.5 \pm$ 0.5\%; WT-DM $12.1 \pm$ 1.0\%; KO-sham $3.6 \pm 0.3 \%$; KO-DM $6.5 \pm$ 0.4\%; fig. 4).

\section{Macrophage Infiltration and Fibroblast Accumulation}

$\mathrm{F} 4 / 80$-positive cells were observed only rarely in WT-sham and $\mathrm{KO}$-sham mice. In contrast, the number of these cells was increased significantly in interstitial lesions in WT-DM mice, but not in KO-DM mice (WT-sham $0.11 \pm 0.03 \%$; WT-DM $1.05 \pm 0.03 \%$; KO-sham $0.10 \pm 0.04 \%$; KO-DM $0.22 \pm 0.04 \%$; fig. 5). FSP-1-positive cells were observed rarely in 

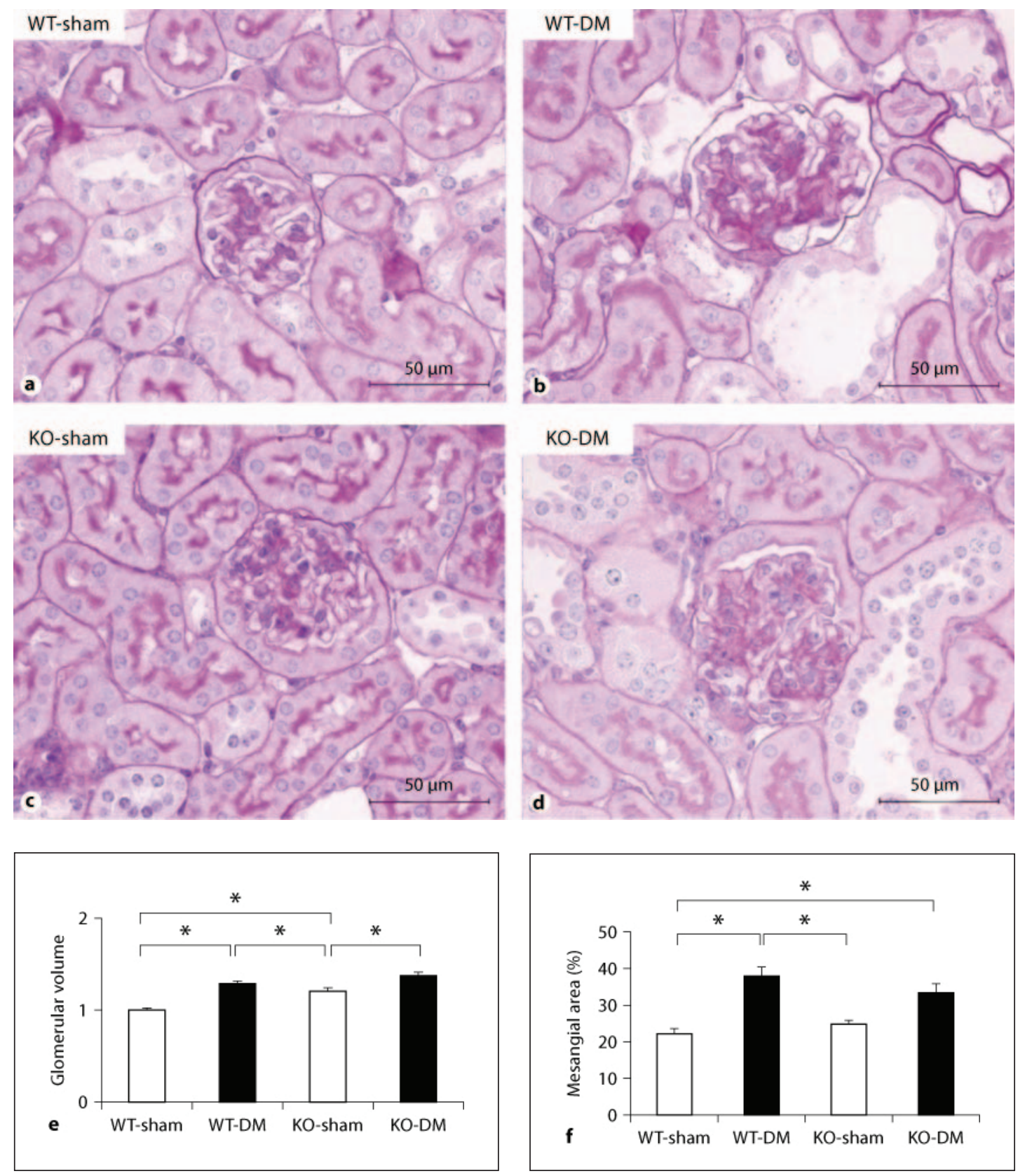

Fig. 3a-f For legend see next page.

WT-sham or KO-sham mice, whereas these cells were increased significantly in interstitial legions of WT-DM mice, but not in KO-DM mice (WT-sham $0.11 \pm 0.02 \%$; WT-DM $0.77 \pm$ 0.03\%; KO-sham $0.18 \pm 0.04 \%$; KO-DM $0.28 \pm 0.04 \%$; fig. 6a-e). $\alpha$-SMA-positive cells were also observed rarely in interstitial lesions in WT-sham or KO-sham mice, whereas these cells were increased significantly in interstitial legions and tubules of WT-DM mice, but not in KO-DM mice (WT-sham $1.7 \pm 0.5 \%$; WT-DM $7.3 \pm 1.0 \%$; KO-sham $1.4 \pm 0.6 \%$; KO-DM $2.6 \pm 0.7 \%$; fig. $6 \mathrm{f}-\mathrm{j})$. These data indicated that OPN knockout attenuated DM-induced macrophage recruitment and fibroblast cell proliferation to the kidney. 

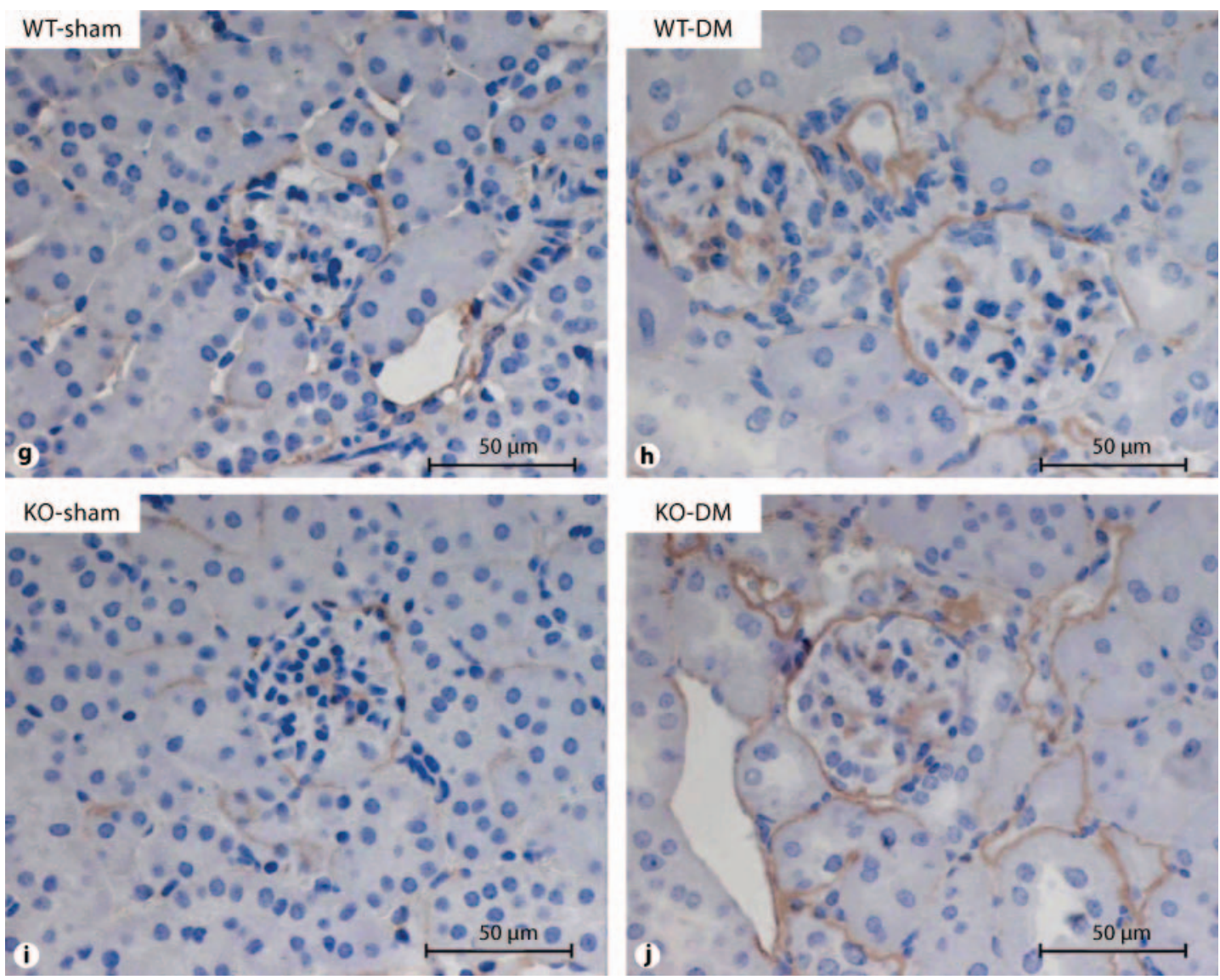

Fig. 3. Representative micrographs of glomeruli (periodic acid-Schiff staining) in WT-sham (a), WTDM (b), KO-sham (c), and KO-DM mice (d). Glomerular volume (e) and mesangial area (f) of WTsham, WT-DM, KO-sham, and KO-DM mice (WT-sham, $\mathrm{n}=5$; WT-DM, $\mathrm{n}=7$; KO-sham, $\mathrm{n}=5$; KO-DM, $n=7) .{ }^{*} p<0.05$. Representative images of immunohistochemistry of type IV collagen protein in WT-sham (g), WT-DM (h), KO-sham (i), and KODM mice (j) . $\mathbf{k}$ Type IV collagen staining area of WT-sham, WT-DM, KO-sham, and KO-DM mice (WT-sham, $\mathrm{n}=5$; WT-DM, $\mathrm{n}=7$; KO-sham, $\mathrm{n}=5$; KO-DM, $\mathrm{n}=7$ ).

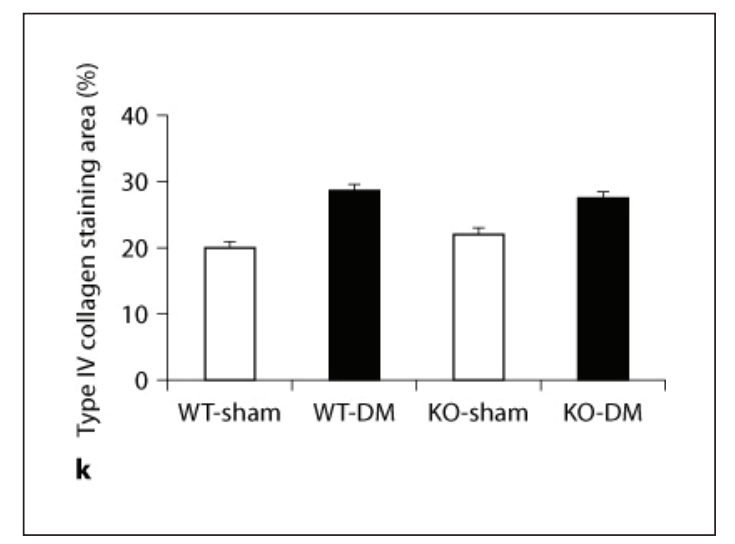

\section{Expression of Fibrosis-Related Genes and TGF- $\beta$}

In both WT-DM and KO-DM mice, DM induction increased renal mRNA expression of type IV collagen (WT-sham $1.00 \pm 0.07$-fold; WT-DM $1.43 \pm 0.05$-fold; KO-sham 0.81 \pm 0.12 -fold; KO-DM $1.28 \pm 0.06$-fold; fig. 7c), fibronectin (WT-sham $1.00 \pm 0.23$-fold; WT-DM $3.56 \pm 0.43$-fold; KO-sham $0.87 \pm 0.05$-fold; KO-DM $2.95 \pm 0.43$-fold; fig. 7 d) and TGF- $\beta$ (WT-sham $1.0 \pm 0.08$-fold; WT-DM $1.51 \pm$ 0.11-fold; KO-sham $0.79 \pm 0.15$ fold; KO-DM $1.35 \pm 0.06$-fold; fig. 7e). However, type I collagen (WT-sham $1.00 \pm 0.10$ fold; WT-DM $3.43 \pm 0.71$-fold; KO-sham $0.57 \pm 0.06$-fold; KO-DM $1.28 \pm 0.15$-fold; fig. 7a) and type III collagen mRNA (WT-sham $1.00 \pm 0.22$-fold; WT-DM $3.47 \pm 0.71$-fold; 

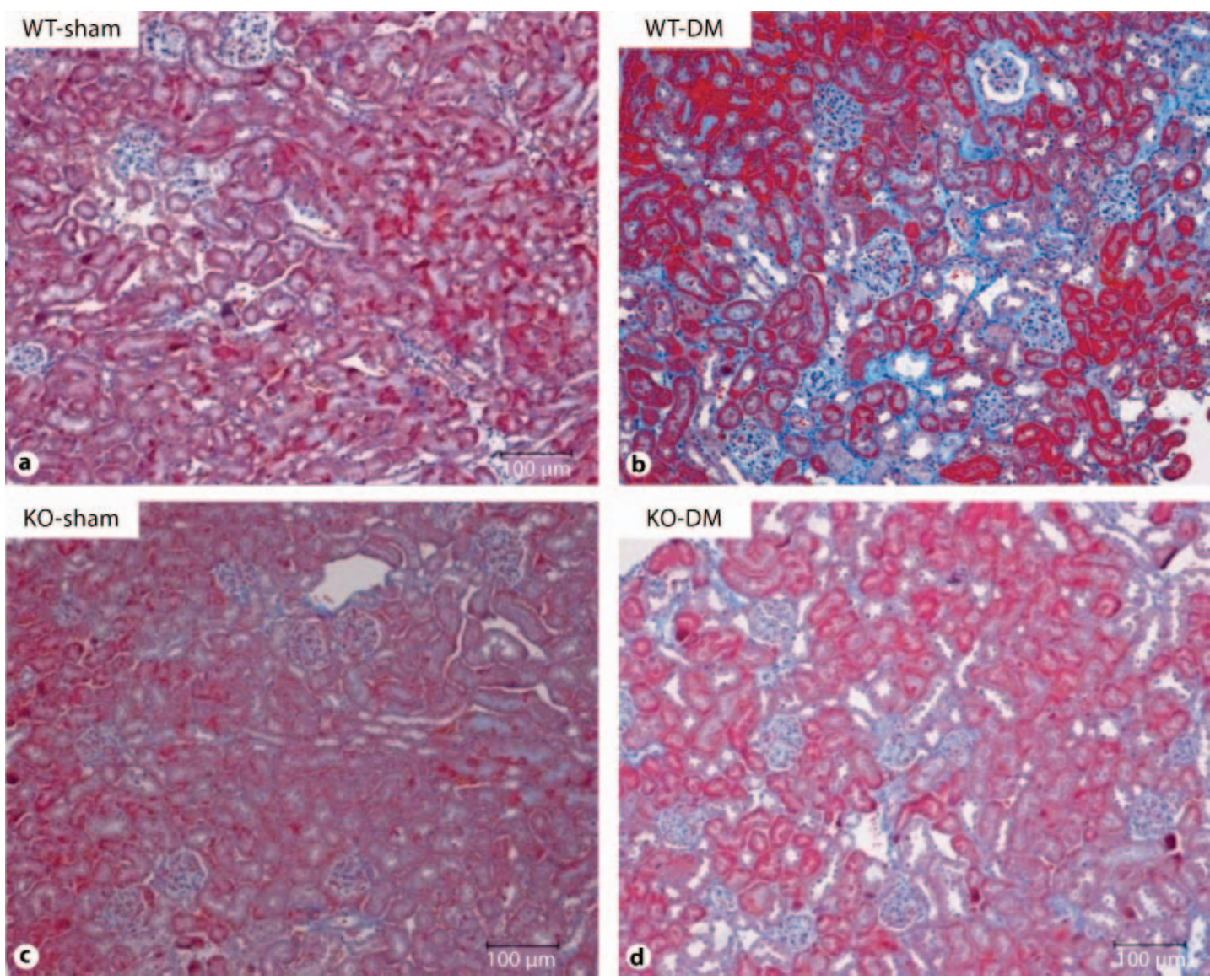

Fig. 4. Representative micrographs of Masson's trichrome-stained renal sections in WT-sham (a), WT-DM (b), KO-sham (c), and KO-DM mice (d). e Bar graph showing semi-quantified renal fibrosis areas (\%) (WT-sham, $\mathrm{n}=5$; WT-DM, $\mathrm{n}=7$; KOsham, $\mathrm{n}=5$; KO-DM, $\mathrm{n}=7$ ). Values are expressed as mean \pm SEM. ${ }^{*} \mathrm{p}<0.05$.

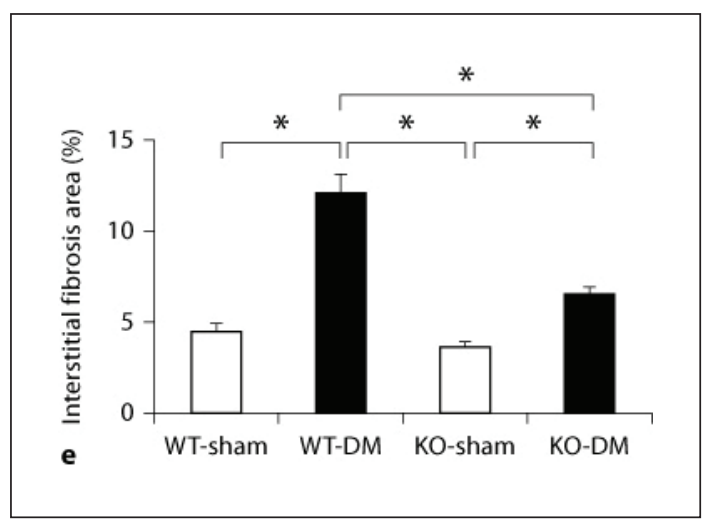

KO-sham $0.68 \pm$ 0.10-fold; KO-DM $1.28 \pm 0.21$-fold; fig. $7 \mathrm{~b}$ ) were increased in WT-DM mice, but not in KO-DM mice. Immunohistochemical analysis also showed that TGF- $\beta$ protein expression in tubules was increased to the same level in WT-DM and KO-DM mice (WT-sham $2.3 \pm$ 0.7\%; WT-DM $10.4 \pm$ 1.7\%; KO-sham $2.2 \pm 0.7 \%$; KO-DM $8.9 \pm 1.7 \%$; fig. $7 f-j)$.

The Role of Oxidative Stress

To determine whether OPN knockout alters DM-induced oxidative stress, we measured expression of NADPH oxidase subunits mRNA including $\mathrm{p} 7^{\text {phox }}$ and $g \mathrm{p} 91^{\text {phox }}$ by real-time 

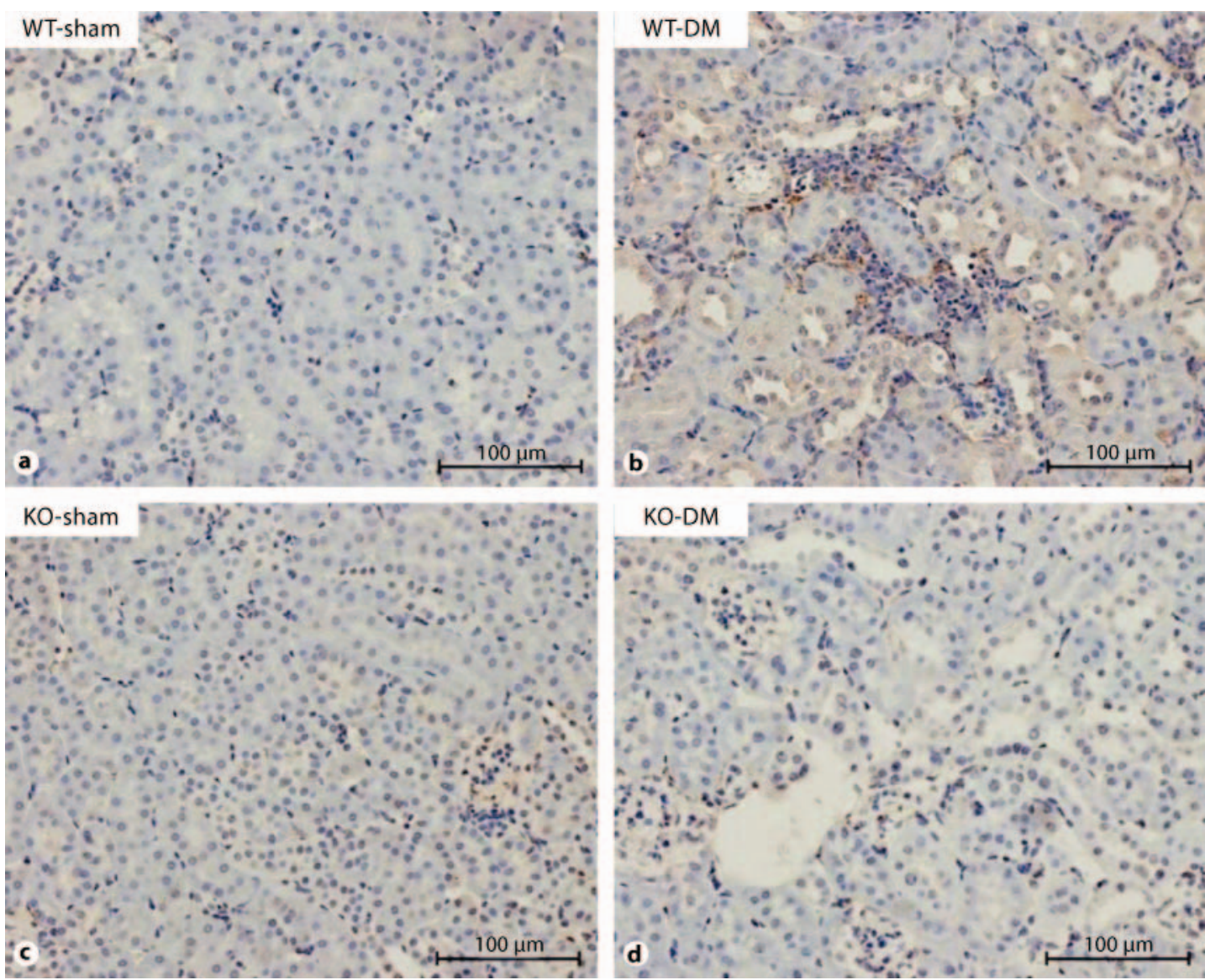

Fig. 5. Representative images of F4/80 (macrophage) in WT-sham (a), WT-DM (b), KO-sham (c), and KO-DM mice (d). e Bar graph showing F4/80positive areas (\%) (WT-sham, $\mathrm{n}=5$; WT-DM, $\mathrm{n}=$ 7; KO-sham, $\mathrm{n}=5$; KO-DM, $\mathrm{n}=7$ ). Values are expressed as mean \pm SEM. ${ }^{*} \mathrm{p}<0.05$.

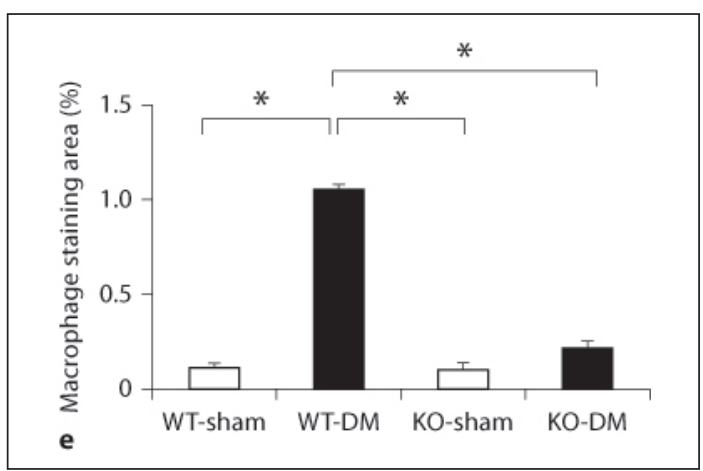

PCR. We found that expression of $47^{\text {phox }}$ (WT-sham $1.00 \pm 0.09$-fold; WT-DM $2.32 \pm 0.21$ fold; KO-sham $0.92 \pm 0.10$-fold; KO-DM $1.50 \pm 0.13$-fold; fig. 8a) and gp91 ${ }^{\text {phox }}$ (WT-sham $1.00 \pm 0.07$-fold; WT-DM $1.91 \pm 0.11$-fold; KO-sham $1.03 \pm 0.08$-fold; KO-DM $1.51 \pm$ 0.09-fold; fig. 8b) was upregulated in WT-DM mice. Deficiency of OPN attenuated these increases in NADPH oxidase subunit genes. To further evaluate the effect of OPN on renal oxidative stress, we measured urinary levels of 8-isoprostane and demonstrated a marked increase in 8-isoprostane excretion in WT-DM mice. In contrast, this increase was reduced significantly by OPN knockout (WT-sham $0.52 \pm 0.09 \mathrm{ng} /$ day; WT-DM $5.04 \pm 0.80 \mathrm{ng} /$ day; KO-sham $0.28 \pm 0.07$ ng/day; KO-DM $2.07 \pm 0.45$ ng/day; fig. $8 \mathrm{c}$ ). 

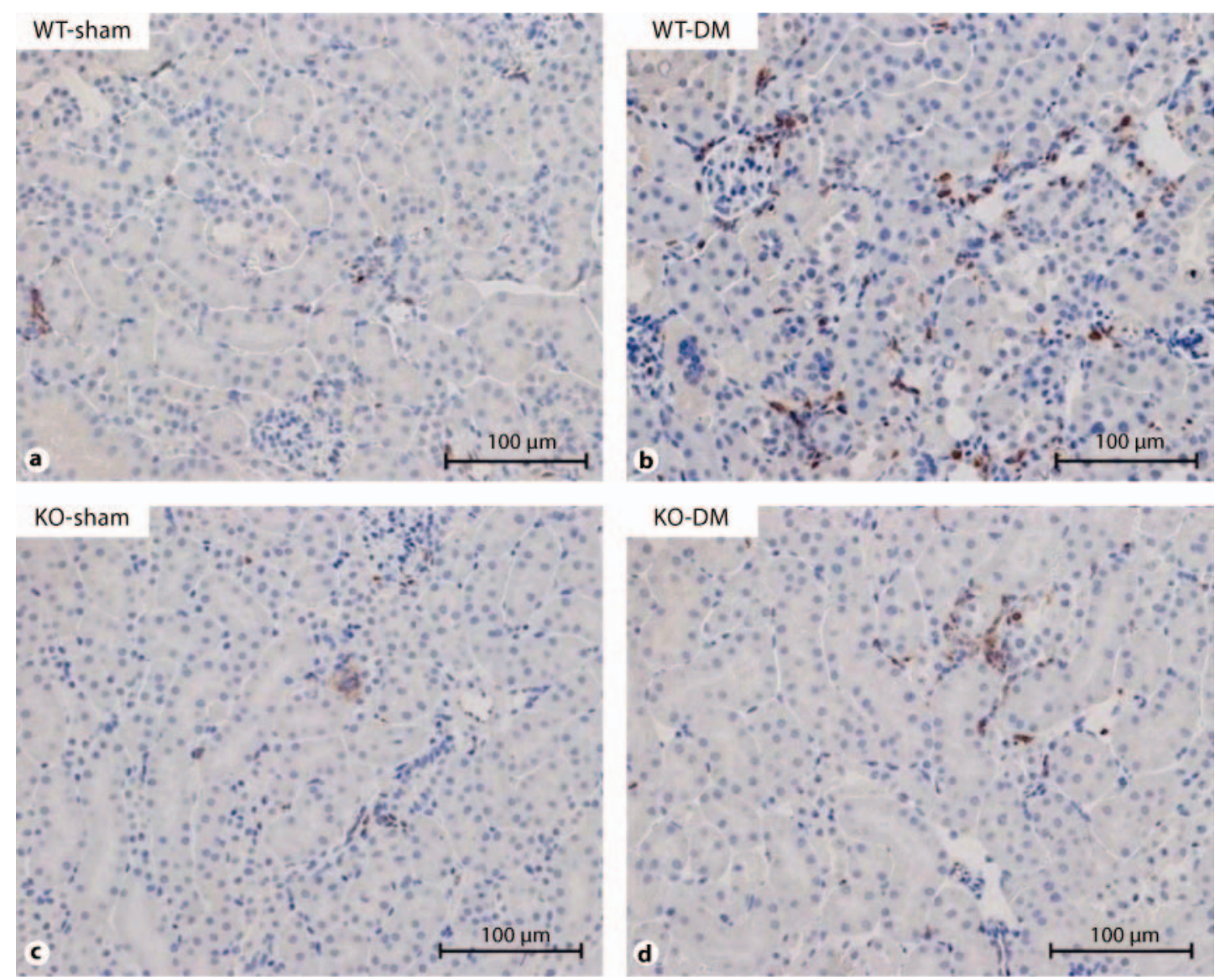

Fig. 6a-e For legend see next page.

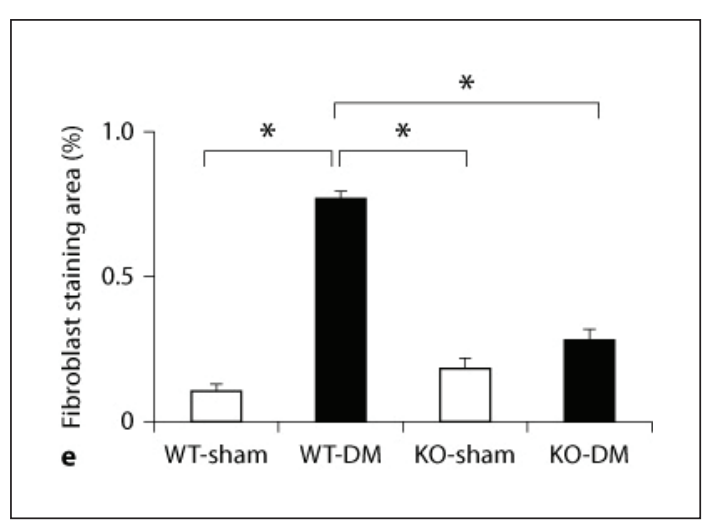

\section{M1 and M2 Macrophage-Associated mRNA Expression}

Renal mRNA expression of M1 (CD11c, TLR4, TNF- $\alpha$, and MCP-1) and M2 (CD163, mannose receptor, MGL-2, and IL-10) macrophage-associated markers was analyzed. Of the M1 macrophage markers, CD11c (WT-sham $1.00 \pm$ 0.10-fold, WT-DM $1.88 \pm 0.22$-fold; online suppl. fig. A), TLR4 (WT-sham $1.00 \pm 0.10$-fold; WT-DM $1.82 \pm 0.08$-fold; online suppl. fig. B), and MCP-1 (WT-sham $1.00 \pm 0.13$-fold; WT-DM $5.02 \pm 0.23$-fold; online suppl. fig. D) were increased significantly in WT-DM mice compared to sham mice. Similarly, expression of the M2 macrophage markers CD163 (WT-sham $1.00 \pm 0.08$-fold; WT-DM $6.16 \pm$ 0.51-fold; online suppl. fig. E), mannose receptor (WT-sham $1.00 \pm 0.05$-fold; WT-DM 4.76 

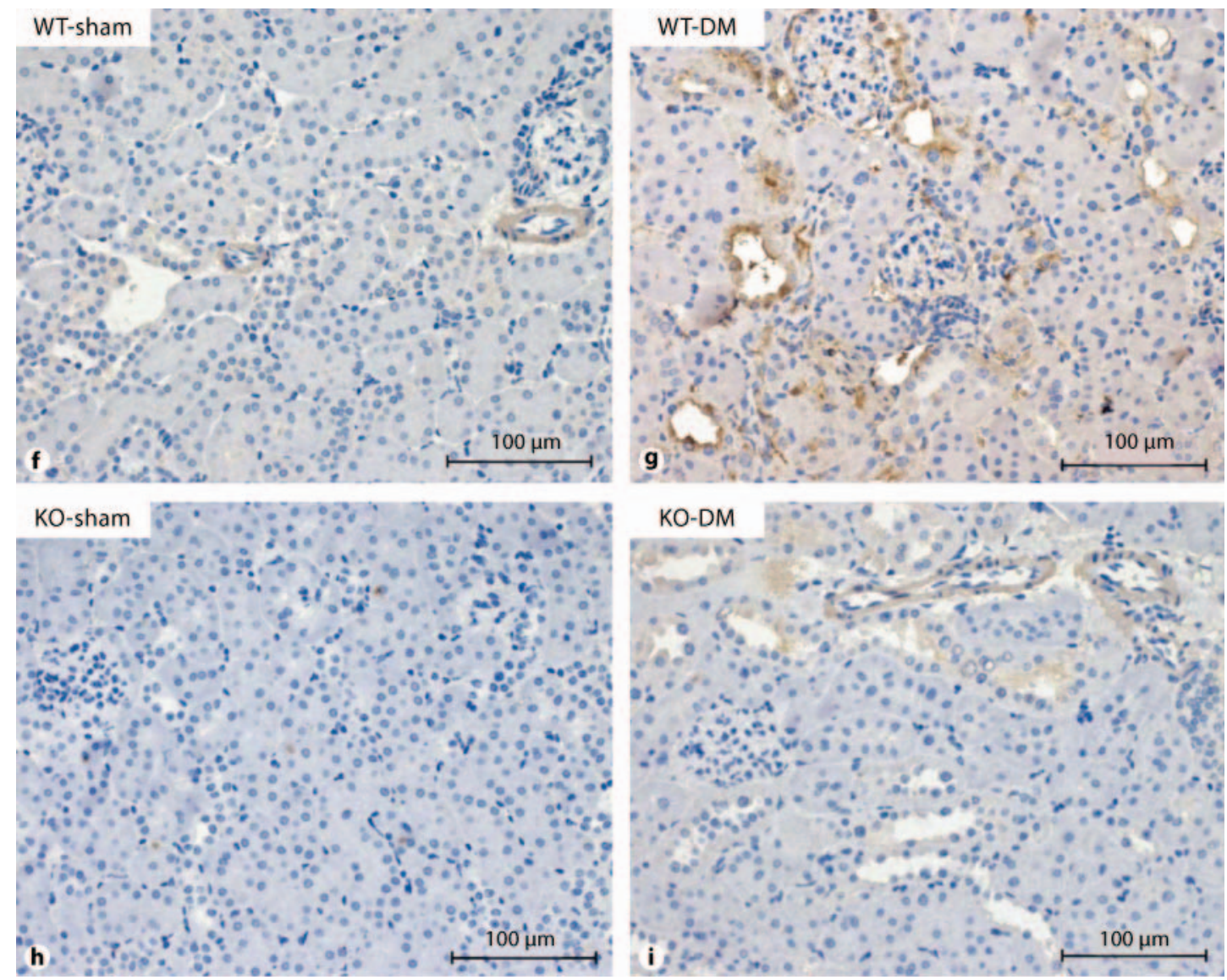

Fig. 6. Representative images of FSP-1 (fibroblast) in WT-sham (a), WT-DM (b), KO-sham (c), and KO-DM mice (d). e Bar graph showing FSP-1-positive areas (\%) (WT-sham, $\mathrm{n}=5$; WT-DM, $\mathrm{n}=7$; KO-sham, $\mathrm{n}=5$; KO-DM, $\mathrm{n}=7$ ). Values are expressed as mean \pm SEM. ${ }^{*} \mathrm{p}<0.05$. Representative images of $\alpha$-SMA in WT-sham (f), WT-DM (g), $\mathrm{KO}$-sham (h), and KO-DM mice (i). j Bar graph showing $\alpha$-SMA staining areas (\%) (WT-sham, $\mathrm{n}=$ 5; WT-DM, $\mathrm{n}=7$; KO-sham, $\mathrm{n}=5$; KO-DM, $\mathrm{n}=7$ ). Values are expressed as mean \pm SEM. ${ }^{*} \mathrm{p}<0.05$.

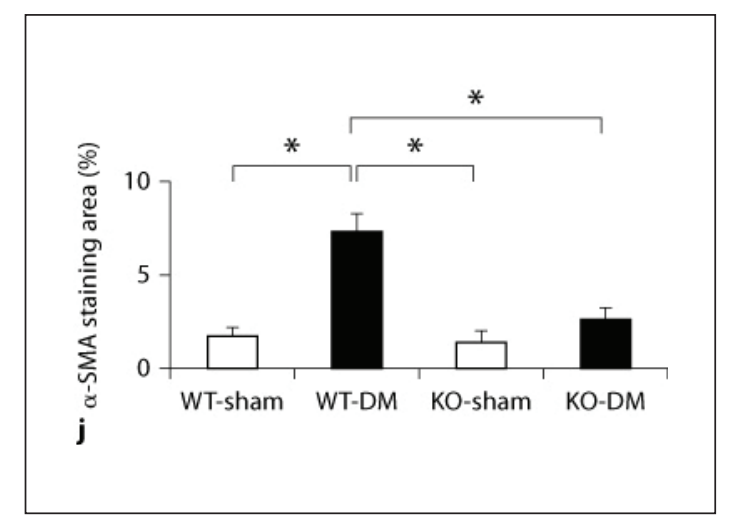

\pm 0.44-fold; online suppl. fig. F) and MGL-2 (WT-sham 1.0 \pm 004-fold; WT-DM $3.8 \pm 0.71$ fold; online suppl. fig. G) was significantly higher in the WT-DM mice than in the sham mice.

Our investigation also showed that KO-DM mice had reduced expression of the M1 macrophage markers CD11c (KO-sham $1.05 \pm 0.09$-fold; KO-DM $1.34 \pm 0.10$-fold; online suppl. fig. A) and MCP-1 (KO-sham $0.47 \pm 0.09$-fold; KO-DM $3.37 \pm 0.03$-fold; online suppl. fig. D) and the M2 macrophage markers CD163 (KO-sham $0.64 \pm 0.06$-fold; KO-DM $2.57 \pm 0.44$-fold; online suppl. fig. E), mannose receptor (KO-sham $0.80 \pm 0.07$-fold; $\mathrm{KO}$ DM $3.10 \pm 0.32$-fold; online suppl. fig. F) and MGL-2 (KO-sham $0.67 \pm 0.03$-fold; KO-DM $1.55 \pm 0.18$-fold; online suppl. fig. G). 


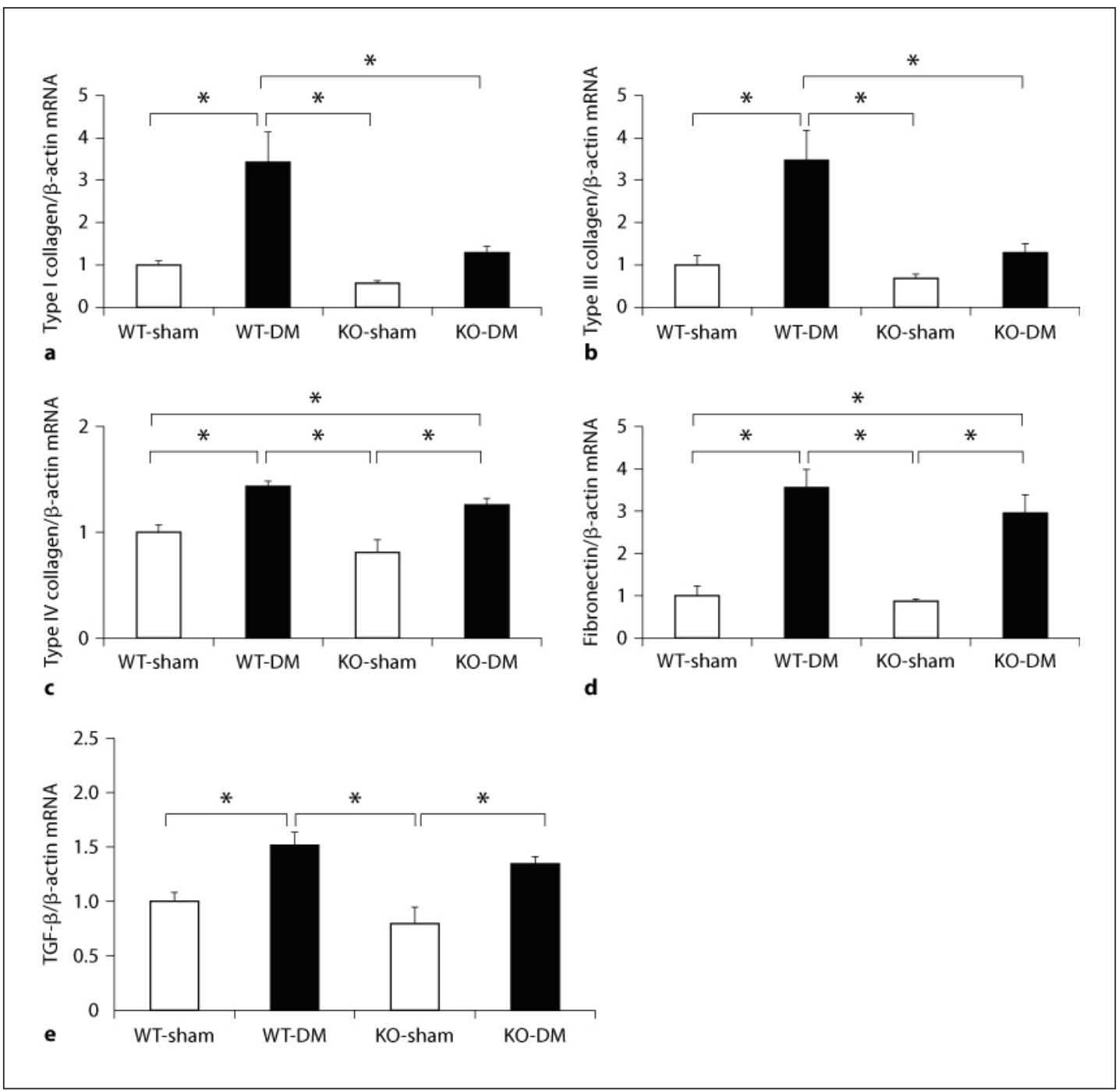

Fig. 7a-e For legend see next page.

\section{Discussion}

Tubulointerstitial fibrosis is important in the progression of renal damage [9], and it has been shown in mice that OPN deficiency attenuates renal tubulointerstitial fibrosis caused by either ischemia/reperfusion injury [10], unilateral ureteral obstruction [11] or angiotensin II [12].

It has been shown in a mouse model of DM that OPN deficiency attenuates mesangial matrix expansion and urine albumin excretion $[13,14]$, although there are no reports as to whether or not OPN plays a critical role in interstitial fibrosis. To clarify this issue, we used OPN knockout mice and induced DM by infusion of STZ.

The major findings of this study were that OPN expression was increased mainly in proximal renal tubules after induction of DM, and that DM induced severe interstitial fibrosis, macrophage infiltration, fibroblast accumulation, and expression of genes related to fibrosis (type I, III collagen) and oxidative stress (p47 ${ }^{\text {phox }}$, gp91 $\left.{ }^{\text {phox }}\right)$. We also demonstrated that these changes were attenuated by OPN knockout. 

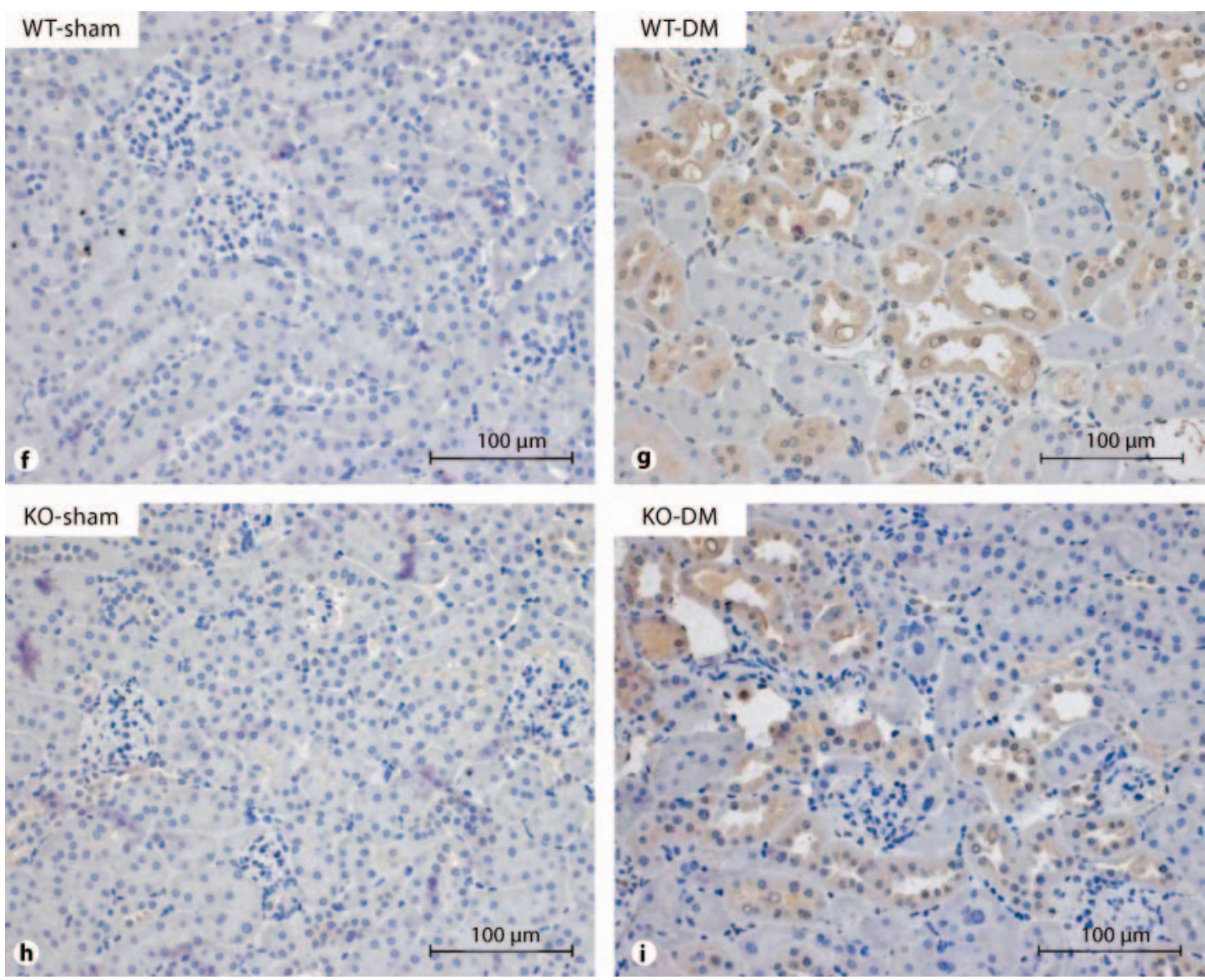

Fig. 7. Real-time PCR for type I collagen (a), type III collagen (b), type IV collagen (c), fibronectin (d), and TGF- $\beta$ (e). WT-sham, $\mathrm{n}=5$; WT-DM, $\mathrm{n}=7$; KO-sham, $\mathrm{n}=5$; KO-DM, $\mathrm{n}=7$. Values are expressed as mean \pm SEM. ${ }^{*} \mathrm{p}<0.05$. Representative images of immunohistochemistry of TGF- $\beta$ protein in WT-sham (f), WT-DM (g), KO-sham (h), and KO-DM mice (i). $\mathbf{j}$ Bar graph showing TGF- $\beta$ staining areas (\%) (WT-sham, $\mathrm{n}=5$; WT-DM, $\mathrm{n}=7$; KO-sham, $\mathrm{n}=5$; KO-DM, $\mathrm{n}=7$ ). Values are expressed as mean \pm SEM. ${ }^{*} \mathrm{p}<0.05$.

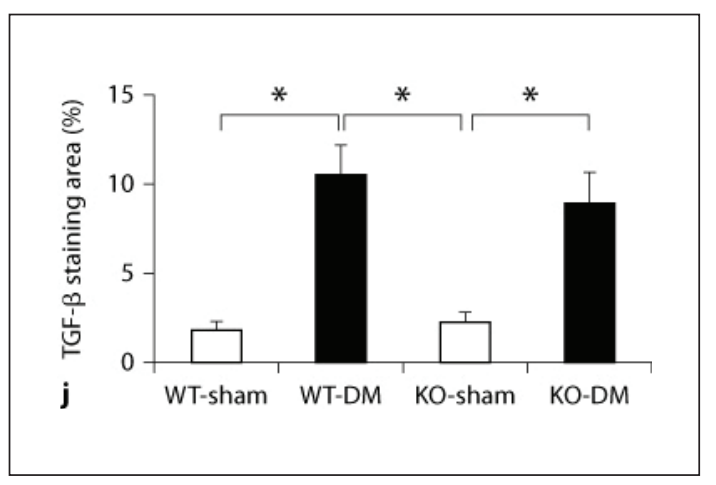

OPN has been reported to be directly or indirectly related to the pathogenesis of DM target organ damage including nephropathy. High glucose induces OPN expression in renal fibroblasts [15], vascular smooth muscle cells [16], monocytes [17], and mesangial cells [18]. There is also evidence that patients with DM have higher concentrations of plasma OPN than non-DM controls [19]. Lorenzen et al. [13] reported that OPN knockout protected against albuminuria and mesangial expansion in DM mice, while Nicholas et al. [14] showed that diabetes induced by STZ was associated with albuminuria and mesangial expansion and that OPN knockout attenuated these abnormal changes. However, in the present study, we showed that OPN knockout reduced interstitial fibrosis, but not mesangial expansion or albuminuria. Furthermore, there was no difference in type IV collagen expression in the mesangium 


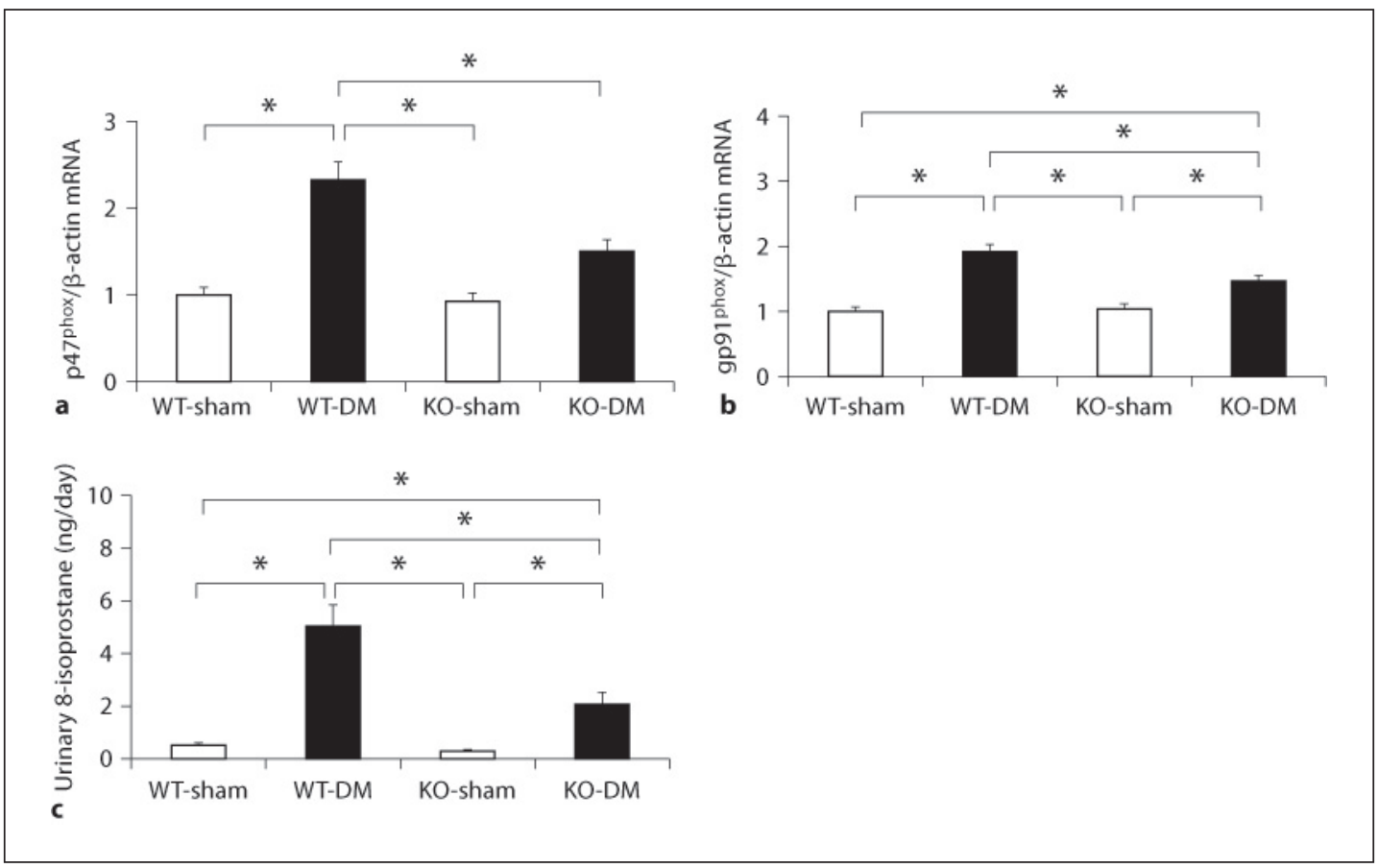

Fig. 8. Real-time PCR for $47^{\text {phox }}(\mathbf{a})$ and gp91 $91^{\text {phox }}(\mathbf{b})$. c Bar graph showing urinary 8-isoprostane excretion measured by ELISA (WT-sham, $\mathrm{n}=5$; WT-DM, $\mathrm{n}=7$; KO-sham, $\mathrm{n}=5$; KO-DM, $\mathrm{n}=7$ ). Values are expressed as mean \pm SEM. ${ }^{*} \mathrm{p}<0.05$.

between WT-DM and KO-DM mice. In their study, Nicholas et al. [14] reported increased glomerular OPN mRNA expression; however, in our study we did not demonstrate OPN expression in the mesangium using immunohistochemistry. The reason for this difference is not clear but may be due to the different mouse strains used for OPN knockout or the procedure of diabetes induction.

It has been reported that macrophages play an important role in tubulointerstitial injury in DM nephropathy [20]. Macrophages contribute to fibroblast proliferation [21] and produce matrix protein such as type I collagen [22]. Macrophages also produce OPN independently, which in turn stimulates production of MCP-1, resulting in macrophage accumulation [23]. The present study showed that OPN deficiency attenuated macrophage recruitment to the kidney, indicating that OPN is a major macrophage chemoattractant that acts either directly or indirectly in DM nephropathy.

Two subtypes of macrophages exist in tissues [24], M1 macrophages and M2 macrophages. M1 macrophages express high levels of proinflammatory cytokines and enhance tissue inflammatory responses, while M2 macrophages express high levels of anti-inflammatory cytokines such as IL-10 and promote tissue repair and enhance fibrogenesis of fibroblasts [25]. Recently, it was reported that expression of M1 and M2 macrophage marker genes was elevated in the renal cortex of DM model mice, and that both M1 and M2 macrophages participated in the development of DM nephropathy [26]. To determine which types of macrophages are influenced by OPN, we compared the expression of M1 and M2 macrophage markers using real-time RT-PCR analyses. M1 macrophage markers including CD11c [26, 32], TLR4 [32], and MCP1 [26], and the M2 macrophage markers CD163 [32], mannose receptor [26, 32], and MGL-2 [26] were elevated in WT-DM mice kidney, whereas OPN defi- 
ciency attenuated DM-induced expression of M1 (CD11c and MCP-1) and M2 macrophage (CD163, mannose receptor, and MGL-2) markers. These results indicate that OPN induces not only M1 macrophages, but also M2 macrophages in STZ-induced DM nephropathy.

Increased production of reactive oxygen species (ROS) may contribute to diabetic nephropathy, with an important source of ROS production being nicotinamide adenine dinucleotide phosphate (NADPH) oxidase. It has been reported that the kidneys of rats with DM have increased expression of NADPH oxidase (p47 ${ }^{\text {phox }}$ and gp91 ${ }^{\text {phox }}$ ) $[27,28]$. In our study, OPN knockout caused significant decreases in the expression levels of $\mathrm{p} 47^{\text {phox }}$ and gp91 ${ }^{\text {phox }}$. Urinary 8-isoprostane excretion, a marker of oxidative stress, also showed a marked increase in WT-DM mice, with this increase being reduced significantly by OPN knockout. These results indicated that OPN acts as a proinflammatory factor that regulates oxidative stress in the kidney.

Recently, we reported that aldosterone upregulated expression of OPN in renal fibroblasts and that OPN-siRNA completely blocked aldosterone-induced collagen synthesis and fibroblast cell proliferation [29]. We also reported recently that high glucose levels upregulated collagen synthesis and OPN expression in renal fibroblasts [15]. In the present study, DM (high glucose) induced fibroblast accumulation and expression of fibrosis-related genes such as type I and type III collagen, and that these changes were attenuated significantly by OPN knockdown. Taken together, these findings indicate that OPN may contribute directly to the pathogenesis of interstitial fibrosis of DM nephropathy by inducing collagen synthesis and renal fibroblast proliferation.

TGF- $\beta$ is a key player in the accumulation of extracellular matrix and is a well-established inducer of epithelial mesenchymal transition (EMT) [30]. In the present study, DM induced similar levels of TGF- $\beta$ expression in both the WT and KO mice in tubular epithelial cells. However, interstitial fibrosis was suppressed in KO-DM mice indicating that OPN is not a mediator of TGF- $\beta$. Hsieh et al. [31] showed that TGF- $\beta$ antisense inhibited high glucose-induced OPN expression in immortalized renal proximal tubular cells, indicating that TGF- $\beta$ is one of the mediators of OPN. However, further study is needed to confirm these associations.

The present study showed that OPN deficiency protected against increases in serum creatinine level resulting from induction of DM, as occurs in WT-DM mice. However, there were no differences in the level of urine albumin excretion and mesangial expansion and glomerular hypertrophy between WT-DM and KO-DM mice, indicating that protection of renal function in $\mathrm{KO}-\mathrm{DM}$ mice may be due to inhibition of tubulointerstitial fibrosis induced by high glucose (DM).

In conclusion, OPN is a promoter of DM-induced inflammation, oxidative stress, and interstitial fibrosis in the kidney. Inhibition of OPN may provide a potential target for therapeutic intervention aimed at preventing progression of kidney damage induced by DM.

\section{Disclosure Statement}

The authors declare that no conflict of interest exists. 


\section{References}

-1 Ziadeh FN, Goldfarb S: The renal tubulointerstitium in diabetes mellitus. Kidney Int 1991;39:464475.

2 Sharma K, Ziyadeh FN: Renal hypertrophy is associated with upregulation of TGF- $\beta 1$ gene expression in diabetic BB rat and NOD mouse. Am J Physiol 1994;267:1094-1101.

-3 Wolf G, Mueller E, Stahl RA, Ziyadeh FN: Angiotensin II-induced hypertrophy of cultured murine proximal tubular cells is mediated by endogenous transforming growth factor- $\beta$. J Clin Invest 1993; 92:1366-1372.

-4 Susztak K, Böttinger E, Novetsky A, Liang D, Zhu Y, Ciccone E, Wu D, Dunn S, McCue P, Sharma $\mathrm{K}$ : Molecular profiling of diabetic mouse kidney reveals novel genes linked to glomerular disease. Diabetes 2004;53:784-794.

-5 Xie Y, Sakatsume M, Nishi S, Narita I, Arakawa M, Gejyo F: Expression, roles, receptors, and regulation of osteopontin in the kidney. Kidney Int 2001;60:1645-1657.

-6 Junaid A, Amara FM: Osteopontin: correlation with interstitial fibrosis in human diabetic kidney and PI3-kinase-mediated enhancement of expression by glucose in human proximal tubular epithelial cells. Histopathology 2004;44:136-146.

-7 Rittling SR, Matsumoto HN, McKee MD, Nanci A, An XR, Novick KE, Kowalski AJ, Noda M, Denhardt DT: Mice lacking osteopontin show normal development and bone structure but display altered osteoclast formation in vitro. J Bone Miner Res 1998;13:1101-1111.

-8 Fukuoka T, Kitami Y, Okura T, Hiwada K: Transcriptional regulation of the platelet-derived growth factor alpha receptor gene via CCAAT/enhancer-binding protein-delta in vascular smooth muscle cells. J Biol Chem 1999;274:25576-25582.

-9 Nath KA: Tubulointerstitial changes as a major determinant in the progression of renal damage. Am J Kidney Dis 1992;20:1-17.

-10 Persy VP, Verhulst A, Ysebaert DK, De Greef KE, De Broe ME: Reduced post-ischemic macrophage infiltration and interstitial fibrosis in osteopontin knockout mice. Kidney Int 2003;63:543-553.

-11 Wolak T, Kim H, Ren Y, Kim J, Vaziri ND, Nicholas SB: Osteopontin regulates renal apoptosis and interstitial fibrosis in neonatal chronic unilateral ureteral obstruction. Kidney Int 2006; 70:17351741.

-12 Wolak T, Kim H, Ren Y, Kim J, Vaziri ND, Nicholas SB: Osteopontin modulates angiotensin II-induced inflammation, oxidative stress, and fibrosis of the kidney. Kidney Int 2009;76:32-43.

-13 Lorenzen J, Shah R, Biser A, Staicu SA, Niranjan T, Garcia AM, Gruenwald A, Thomas DB, Shatat IF, Supe K, Woroniecki RP, Susztak K: The role of osteopontin in the development of albuminuria. J Am Soc Nephrol 2008;19:884-890.

14 Nicholas SB, Liu J, Kim J, Ren Y, Collins AR, Nguyen L, Hsueh WA: Critical role for osteopontin in diabetic nephropathy. Kidney Int 2010;77:588-600.

15 Desilva VR, Okura T, Miyoshi K, Irita J, Kurata M, Enomoto D, Nagao T, Jotoku M, Higaki J: Role of osteopontin in diabetic nephropathy. Ann Res J SLSAJ 2010;10:32-36.

-16 Takemoto M, Yokote K, Yamazaki M, Ridall AL, Butler WT, Matsumoto T, Tamura K, Saito Y, Mori S: Enhanced expression of osteopontin by high glucose in cultured rat aortic smooth muscle cells. Biochem Biophys Res Commun 1999;258:722-726.

-17 Samuvel DJ, Sundararaj KP, Li Y, Lopes-Virella MF, Huang Y: Adipocyte-mononuclear cell interaction, Toll-like receptor 4 activation, and high glucose synergistically up-regulate osteopontin expression via an interleukin 6-mediated mechanism. J Biol Chem 2010;285:3916-3927.

-18 Sodhi CP, Phadke SA, Batlle D, Sahai A: Hypoxia and high glucose cause exaggerated mesangial cell growth and collagen synthesis: role of osteopontin. Am J Physiol Renal Physiol 2001;280:667-674.

-19 Yan X, Sano M, Lu L, Wang W, Zhang Q, Zhang R, Wang L, Chen Q, Fukuda K, Shen W: Plasma concentrations of osteopontin, but not thrombin-cleaved osteopontin, are associated with the presence and severity of nephropathy and coronary artery disease in patients with type 2 diabetes mellitus. Cardiovasc Diabetol 2010;9:70.

-20 Chow F, Ozols E, Nikolic-Paterson DJ, Atkins RC, Tesch GH: Macrophages in mouse type 2 diabetic nephropathy: correlation with diabetic state and progressive renal injury. Kidney Int 2004;65: $116-128$.

21 Chow FY, Nikolic-Paterson DJ, Atkins RC, Tesch GH: Macrophages in streptozotocin-induced diabetic nephropathy: potential role in renal fibrosis. Nephrol Dial Transplant 2004;19:2987-2996. 
-22 Vaage J, Lindblad WJ: Production of collagen type I by mouse peritoneal macrophages. J Leukoc Biol 1990;48:274-280.

-23 Zheng W, Li R, Pan H, He D, Xu R, Guo TB, Guo Y, Zhang JZ: Role of osteopontin in induction of monocyte chemoattractant protein 1 and macrophage inflammatory protein $1 \beta$ through the NF- $\kappa B$ and MAPK pathways in rheumatoid arthritis. Arthritis Rheum 2009;60:1957-1965.

- 24 Wang Y, Harris DC: Macrophages in renal disease. J Am Soc Nephrol 2011;22:21-27.

-25 Song E, Ouyang N, Hörbelt M, Antus B, Wang M, Exton MS: Influence of alternatively and classically activated macrophages on fibrogenic activities of human fibroblasts. Cell Immunol 2000;204: $19-28$.

-26 Suzuki H, Kato I, Usui I, Takasaki I, Tabuchi Y, Oya T, Tsuneyama K, Kawaguchi H, Hiraga K, Takasawa S, Okamoto H, Tobe K, Sasahara M: Characterization of diabetic nephropathy in CaM kinase II $\alpha$ (Thr286Asp) transgenic mice. Biochem Biophys Res Commun 2009;379:38-42.

-27 Asaba K, Tojo A, Onozato ML, Goto A, Quinn MT, Fujita T, Wilcox CS: Effects of NADPH oxidase inhibitor in diabetic nephropathy. Kidney Int 2005;67:1890-1898.

-28 Onozato ML, Tojo A, Goto A, Fujita T, Wilcox CS: Oxidative stress and nitric oxide synthase in rat diabetic nephropathy: effects of ACEI and ARB. Kidney Int 2002;61:186-194.

29 Irita J, Okura T, Kurata M, Miyoshi K, Fukuoka T, Higaki J: Osteopontin in rat renal fibroblasts: functional properties and transcriptional regulation by aldosterone. Hypertension 2008;51:507-513.

-30 Hills CE, Squires PE: TGF- $\beta 1$-induced epithelial-to-mesenchymal transition and therapeutic intervention in diabetic nephropathy. Am J Nephrol 2010;31:68-74.

-31 Hsieh TJ, Chen R, Zhang SL, Liu F, Brezniceanu ML, Whiteside CI, Fantus IG, Ingelfinger JR, Hamet P, Chan JS: Upregulation of osteopontin gene expression in diabetic rat proximal tubular cells revealed by microarray profiling. Kidney Int 2006;69:1005-1015.

- 32 Ito A, Suganami T, Yamauchi A, Degawa-Yamauchi M, Tanaka M, Kouyama R, Kobayashi Y, Nitta N, Yasuda K, Hirata Y, Kuziel WA, Takeya M, Kanegasaki S, Kamei Y, Ogawa Y: Role of CC chemokine receptor 2 in bone marrow cells in the recruitment of macrophages into obese adipose tissue. J Biol Chem 2008;51:35715-35723. 